\title{
A Brief Analysis of the Current Situation and Development Trend on Green Transportation Standard System
}

\author{
Wei Wang ${ }^{1 *}$, Juan Han $^{1}$ and Yanlei Shi ${ }^{1}$ \\ ${ }^{1}$ Research Center for Standards and Metrology, China Academy of Transportation Sciences, Beijing, 100029, China.
}

\begin{abstract}
It is great significance to improve green transportation standards system for promoting the construction of ecological civilization and the sustainable development of recycling and low carbon of transportation. This paper summarizes the status of green transportation standards system and the progress of standard publication and revision. According to the key areas and links of green transportation development, the development trends of green transportation and the requirement of green transportation standards were analysed, and policy recommendations for improving the construction of green transportation standards system was proposed. The paper is trying to provide decisive support for the industry to promote the development of green transportation standardization.
\end{abstract}

\section{Introduction}

Green transportation is an important strategy for the transportation industry to strengthen the construction of ecological civilization and achieve circular low-carbon sustainable development. In 2013, Ministry of Transport (MOT) published Guiding Opinions on Accelerating the Development of Green Cycle and Low-Carbon Transportation that proposed the development goal of basically establishing a green cycle and low-carbon transport system by 2020[1]. To promote green transportation construction, it is necessary to adhere to resource conservation and environmental protection, pay attention to the organic unity of development speed, quality, and efficiency, and strengthen the top-level design of the standard system, give full play to the role of standards[2-3]. In order to coordinate the development of green transportation standardization, MOT issued Green Transportation Standard System (2016) in 2016, which proposed 221 important energy conservation and environmental protection standards. The standards are of great significance to promote the application of advanced energy conservation and environmental protection technology products, reducing the impact of ecological environment, improving energy efficiency, and the transportation energy structure[4].

In the past few years, MOT had taken the green transportation standard system as a guide to strengthen the revision and implementation of green transportation standards, and has made great progress in structural optimization, resource conservation, technological innovation, and management improvement[5]. However, compared with the requirements for high-quality development of transportation in the new era, current green transportation standardization work of China cannot fully support the needs of the industry's ecological protection, resource conservation, pollution prevention, and energy conservation and emission reduction. Therefore, it is great significance for promoting the green development of transportation to systematically combine the development basis of the green transportation standard system, deeply analysis of the development trend of green transportation, and put forward strategies and suggestions of standardization development.

\section{Summary of Green Transportation Standard System}

In 2013, MOT published Opinions on Strengthening the Work of Standardization of Transportation, which for the first time proposed that organizing the research work on green transportation standard system[6]. In 2016, MOT published 13th Five-Year Plan for Development of Transportation Standardization and 13th Five-Year Plan for Development of Transportation Energy Conservation and Environmental Protection, which determined the direction of formulation and revision about green transportation standards development, and proposed the development goal of green transportation systems and standards to further improve, clarified the work task of publishing green transportation standard system. 


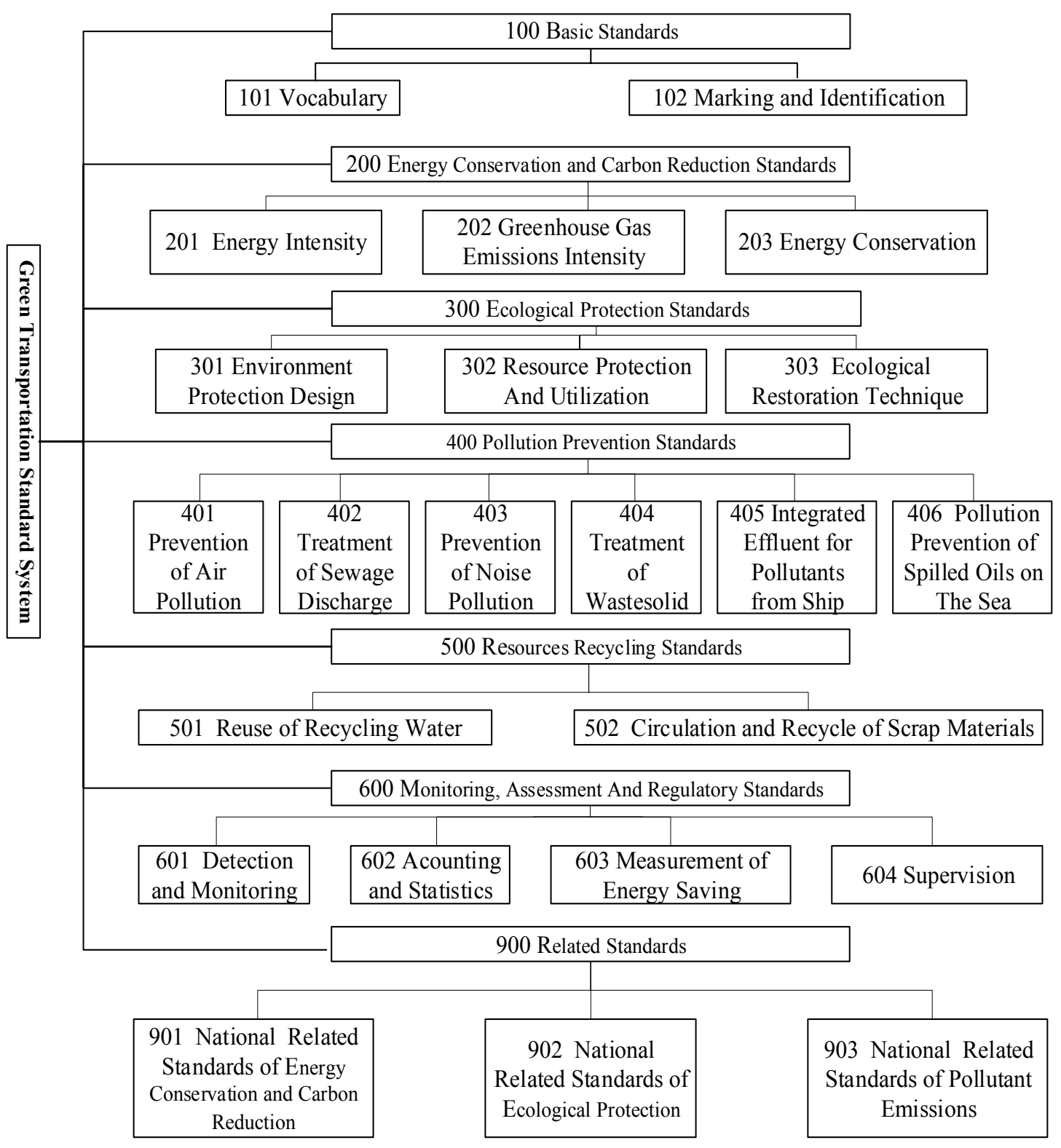

Figure 1 Architecture of green transportation standard system by MOT

Green Transportation Standard System (2016) includes product service standards and engineering construction standards, which formulated by MOT, related to energy conservation and environmental protection of highways and waterways. The standard architecture design comprehensively considers the connotation of green transportation, the key tasks of energy conservation and environmental protection during the China's Thirteenth Five-Year Plan, and energy conservation and environmental protection technology and management standardization requirements of highway and water transportation. The system divided into 7 categories, such as basic standards, energy conservation and carbon reduction standards, ecological protection standards, pollution prevention standards, resources recycling standards, monitoring, assessment and regulatory standards, and related standards (see Figure 1). The standard system includes 221 standards, which divided into 3 basic standards, 48 energy conservation and carbon reduction standards, 14 ecological protection standards,
52 pollution prevention standards, 14 resources recycling standards, 54 monitoring, assessment and regulatory standards, and 36 related national standards for energy conservation and environmental protection. The number of items published in the standard system is 136, which including 48 national standards and 78 industry standards, and the number of items that to be formulated is 95, which including 15 national standards and 80 industry standards.

\section{Progress of Green Transportation Standards}

In accordance with the standard demand planning of the Green Transportation Standard System (2016), MOT has strengthened the work of revising the energy-saving and environmental protection standards. Since the issue of standard system, 23 new standards have been issued, and another 23 standard plans are being implemented. Statistics show in Table 1. 
Table 1 Quantity statistics of green transportation standards by MOT

\begin{tabular}{|c|c|c|}
\hline Category of System & $\begin{array}{c}\text { Number of } \\
\text { Current Effective } \\
\text { Standards } \\
\end{array}$ & $\begin{array}{c}\text { Number of } \\
\text { Standards to } \\
\text { be formulated }\end{array}$ \\
\hline 100 Basic Standards & 0 & 0 \\
\hline $\begin{array}{c}200 \text { Energy } \\
\text { Conservation and } \\
\text { Carbon Reduction } \\
\text { Standards }\end{array}$ & 7 & 8 \\
\hline $\begin{array}{c}300 \text { Ecological } \\
\text { Protection Standards }\end{array}$ & 3 & 0 \\
\hline $\begin{array}{c}400 \text { Pollution } \\
\text { Prevention Standards }\end{array}$ & 8 & 4 \\
\hline $\begin{array}{l}500 \text { Resources } \\
\text { Recycling Standards } \\
600 \text { Monitoring, }\end{array}$ & 0 & 1 \\
\hline $\begin{array}{l}\text { Assessment and } \\
\text { Regulatory Standards }\end{array}$ & 5 & 10 \\
\hline Total & 23 & 23 \\
\hline
\end{tabular}

For energy conservation standards, newly issued standards include limits of fuel consumption for commercial vehicle, energy consumption evaluation methods of port equipment, energy efficiency grades evaluation of expressway electromechanical mechanical and electrical facilities, shore-to-ship power supply system technical conditions, etc. For ecological protection standards, they include drawings for highway revegetation design, and highway vegetation restoration materials. For pollution prevention Standards, they include sewage treatment facility in highway service areas, highway noise barriers, construction of terminal vapor recovery facilities, oil fingerprint identification of water oil spill based on stable isotope analysis, oil booms, belt skimmer, etc. For statistical assessment standards, they include the main pollutants statistical indexes and accounting method of transportation, and technical requirements for the assessment of green transportation facilities.

Standards under development include limits of fuel consumption for natural gas commercial vehicles, energy efficiency of commercial vehicles and intensity levels of carbon dioxide emission, oil-water separation systems for oil spill control, chemical adsorbents, bio-bitumen for pavements, technical requirements for pollutant emissions from ship, and the method of checking and measuring energy utilization efficiency for port crane, investment statistical indexes and accounting method of transportation environmental protection, requirements for drafting of compilation of ship's air pollutant emission list, technical specifications for environmental impact assessment of highway network planning, inland waterway and port layout planning, etc.

\section{Trend Analysis of Green Transportation Standards Development}

Compared with the new ideas and new strategic requirements of national ecological civilization construction, the problems of relatively extensive development modes of transportation, unreasonable transportation structure, incomplete green transportation governance system, and improvement of governance capacity still exist[7]. At the end of 2017, combined with the relevant requirements from central authorities, discontinuous characteristics and development goals of the industry development, MOT issued the Opinions on Comprehensively and Deeply Promoting the Development of Green Transportation. The opinions focus on key areas and key links, and key issues, make up for shortcomings, strength weaknesses from the optimization of transportation structure, organize innovation, green travel, intensive resources, equipment upgrades, pollution prevention, ecological protection and other aspects, and opinions promote the formation of green development methods and lifestyles. Moreover, the opinions further clearly propose the need to improve the green transportation system tasks of the standard system[8-9]. The future development of green transportation should be driven by passive adaptation to advance, promoted by pilots to move forward in an allround way, and promoted by the government to move towards common governance for the entire people. Moreover, the future development should be used to improve the quality of transportation services by green transportation infrastructure and clean and efficient transportation equipment, thereby forming a spatial pattern, industrial structure, production mode and lifestyle of resources conservation and environment protecting.

In the future, the development of green transportation should adhere to the goal of resource conservation and environmental friendliness, promote the formation of green transportation development methods and green travel modes, and promote the harmonious unity of transportation and the ecological environment. In terms of strengthening ecological environmental protection, it is necessary to strictly abide by the ecological redline, promote ecological selection of line and site, strengthen design of ecological environmental protection, and strengthen protection and restoration of ecosystem. In terms of promoting intensive and economical use of resources, it is necessary to coordinate and organize spatial planning and layout, vigorously carry out construction materials, recycling and comprehensive utilization of scrap materials. In terms of energy conservation, emission reduction and pollution prevention, it is necessary to promote the application of clean energy, effectively preventing pollutant emissions from highway noise, and water and air of ships and ports. In terms of improving the green transportation development model, it is necessary to vigorously implement priority strategies for public transportation, actively promote technologies and products of green transportation, and accelerate the innovation and promotion of advanced energy-saving and low-carbon applicable technologies and products. 


\section{Policy Recommendations for Improving the Green Transportation Standard System}

\subsection{Strengthen the dynamic management of green transportation standard system}

It is necessary to benchmark international and foreign transportation energy conservation and environmental protection standards, and to track changes in important technical indicators and research and development of advanced technology products. In addition, it is necessary to set up the dynamic adjustment mechanism of the green transportation standard system, and to Promote the rapid transformation of scientific and technological innovation achievements of green transportation, energy saving and environmental protection into standards in China.

\subsection{Strengthen the pre-research and formulation of key green transportation standards}

Combined with the key point of construction and development for green transportation system, it is necessary to strengthen the formulation of environmental protection standards for transportation infrastructure, and to focus on promoting the formulation and revision of design standards for green highway, green port, and green channel engineering. In order to reduce and prevent the emission of traffic pollutants, it is necessary to carry out formulation of technical standards, such as the control of air pollution emissions from operating vehicles, ships, and construction equipment, noise pollution prevention and sewage discharge in waterway area, resource utilization of solid waste resources, and the control of noise for extralong tunnels and exhaust pollution. It is necessary to improve standards of transportation energy-saving technologies and product, expand port applications for liquefied natural gas (LNG) clean energy and shore power energy-saving technology standards, promote the development of energy-saving and transformation standards for boom lifting equipment, improve the construction of relevant standards for new energy vehicle applications, and carry out standard development of monitoring system for public transportation vehicle charging facility and electric power supply system for long-distance single-phase.

\subsection{Emphasize the demonstration and leading role of green transportation standards}

It is necessary to actively assist the construction of the Xiong'an New Area in Hebei province, to base on sustainable transportation development and solving traffic congestion, to establish and carry out forward-looking and high-quality green transportation standards, to increase the proportion of public transportation trips, and to establish a new type of public transport system with high-quality services and diverse forms, and to create a demonstration model of green and intelligent transportation system standardization[10]. Relying on the demonstration projects such as scientific and technological demonstration project of MOT, transportation quality project, national public transport metropolis, transportation energy conservation and emission reduction, etc., it is necessary to strengthen full implementation of green transportation standards, to bring along utilization and extension of new technologies, products and methods for transportation energy conservation and environmental protection in the whole country.

\section{Acknowledgments}

This work is financially supported by National Key R\&D Program of China (NO. 2017YFF0207501), Strategic, Planning \& Policy Research Program for Transportation of China (NO.2019-9-5) and MOT Standardization Research Project (NO. 2019-99-064).

\section{References}

1. Ministry of Transport of the People's Republic of China. (2013) Guiding opinions on accelerating the development of green cycle and low-Carbon transportation.

http://www.gov.cn/gongbao/content/2013/content 24 66586.htm.

2. C.T., Yang. (2013) Developing green transportation and building a beautiful China. China Water Transport, 12: 3.

3. M.Y., Yu. (2014) Standards lead green transportation to go further. Chinese Transportation News, 2014-0912 (005).

4. Ministry of Transport of the People's Republic of China. (2016) Green transportation standard system. http://zizhan.mot.gov.cn/zfxxgk/bnssj/kjs/201701/t2 0170116 2154566.html.

5. Y.B., Luan, Q.F., Meng. (2018) Green transportation opens new picture of beautiful China-A summary of green development of transportation since the 18th national congress of the CPC. People's Transportation, 7: 26-28.

6. Ministry of Transport of the People's Republic of China. (2013) Guiding opinions on Strengthening Transport Standardization. http://zizhan.mot.gov.cn/zfxxgk/bnssj/kjs/201309/t2 0130917_1484546.html.

7. H.Z., Chen. (2006) Thinking on the construction of green transportation system based on sustainable development. Ecological Economy, 1: 117-120.

8. Policy Research Office of MOT. (2018) Promoting the development of green transportation and serving the construction of a strong transportation countryInterpretation of opinions on comprehensively and deeply promoting the development of green transportation. People's Transportation, 1: 40-43.

9. Z.H., Feng, J, Guo, H.Y., Zhang. (2018) Quality improvement of green transportation-opinions on comprehensively and deeply promoting the development of green transportation. China Highway, 


\section{3: 54-56.}

10. The State Council of the People's Republic of China. (2018) Planning framework of Xiong'an New Area in Hebei province. http://www.gov.cn/xinwen/201804/21/content 5284800.htm. 